\title{
Arterial Stiffness: A New Biomarker to be Measured
}

\author{
Hasan Obeid, ${ }^{1}$ Valentin Ouedraogo, ${ }^{2}$ and Magid Hallab ${ }^{3,}{ }^{*}$ \\ ${ }^{1}$ INSERM-PARCC U970, Paris, France \\ ${ }^{2}$ Laboratory of Physiology, Cheikh Anta Diop University of Dakar (Senegal) \\ ${ }^{3}$ Gerontology Department, Nantes University, Nantes, France \\ "Corresponding author: Magid Hallab, 17, Lafontaine, 44460 Saint Nicolas de Redon, France. Tel: +33-660872320, E-mail: magid.hallab@gmail.com
}

Received 2016 September 20; Accepted 2017 February 28.

\begin{abstract}
Arterial Stiffness (AS) is of great interest in the prediction and the management of cardiovascular events. The evaluation of AS using 2 points of measurement of the pulse wave velocity was of considerable increasing interest in the early 21st century. This paper aimed at focusing on the modeling of different measurement methods. Several measurement techniques are presented. A review of the bibliography and an explanation of the link between cardiovascular events and arterial stiffness are summarized. Novel apparatus that were developed for determining arterial stiffness claimed superiority over pioneering methods either through greater simplicity of use, better repeatability, or a more pertinent arterial pathway.
\end{abstract}

Keywords: Cardiovascular Diagnostic Technique, Pulse Wave Velocity, Arteriosclerosis, Preventive Medicine

\section{Cardiovascular Diseases in Public Health}

Overall, $10 \%$ to $20 \%$ of heart attacks occur with no diabetes, hypertension, cholesterol or smoking (1). When stent or coronary angiography is installed, the patients are informed that they have stiff arteries, or familial arteriosclerosis. Stresses due to the pain of the heart attack, disability, and costs for public health in general and for the family are important issues. Nevertheless, today, there is no preventive action in the direction of families, while there exists non-invasive medical devices that can measure the aging of arteries in the general population.

Cardiovascular diseases (CVDs) remain the leading cause of deaths worldwide. Approximately 30\% of all deaths consisting 20 million people will be caused by CVDs in 2015. Of these, an estimated 8 million are due to coronary heart disease and 7 million to stroke (2).

With aging, an increase of $50 \%$ in the rate of heart failure and stroke is expected for the next 25 years (3). Heart disease and stroke are the second cause of disability in the USA. People may live with heart disease for years or decades. It can severely limit their ability to work. Studies have estimated that heart disease is now the reason for $17 \%$ of all health costs in the US (4). Stroke costs are about 6.76 Billion $€$ every year in France.

The economic burden related to the management of vascular diseases (heart attack, stroke, cognitive impairment, and heart and kidney failure) remains considerable. The direct and indirect costs are around 28 billion $€$ every year in France.

Pulse wave velocity (PWV) is a very good surrogate for aging of the arteries (5). It has been studied for the past
40 years and it is now considered as an independent cardiovascular risk factor to be measured in hypertensive patients to detect silent organ damage. This was validated by the European society of hypertension and that of cardiology in 2013, and conducted in 2016: PWV is to be considered at the same level of proof of that of microalbuminuria in class IIa level B. Pulse Wave Velocity has a history of more than 25 longitudinal follow up studies for over 15 years, 4 meta-analyses with individual data, 200 European medical researches centers, and over 3000 scientific papers every year since 2012 .

\section{Classical Cardiovascular Risk Factors}

The causes of cardiovascular disease were determined by prospective epidemiological studies, since 1950 (Framingham). In addition to high blood pressure, the 2 most frequent risk factors are diabetes and hypercholesterolemia. In hypertension, there is $28 \%$ of white coat syndrome and about $17 \%$ of masked hypertension this is about $45 \%$ of bad targeting $(6,7)$.

Several studies are based on data from the Framingham study, including systolic and diastolic blood pressure, aging (8), the low density lipoprotein (LDL)-cholesterol, triglycerides, high density lipoprotein (HDL)-cholesterol (9), hypertension (10), and PWV (11), which are all risk factors leading to cardiovascular disease.

A strong association has been found between the risk of cardiovascular event and alterations in the structure and/or parietal vascular function $(4,12)$. The stiffness of the vascular tree is physiologically related to aging in the aortic path that is constituted of $80 \%$ elastic fibers. The upper 
and lower limbs are muscular. Authors agree that arterial compliance is not correlated with age in limb arteries. The risk ratio of PWV is 2.3 while that of diabetes is 1.7; hypertension 1.8; cholesterol 2.0, and tobacco 1.9 (13). These are modifiable classical risk factors.

The non-modifiable risk factors are gender, age, and heredity. Risk markers are represented by psychosocial factors, stress, alcohol, C-reactive protein (CRP), fibrinogen, hyperhomocysteinemia, obesity, sedentarily, waist/hip ratio, dietary patterns, physical activity, consumption of alcohol, and blood apolipoproteins, which are known as confounding factors (14).

Pulse wave velocity assesses arterial stiffness. It is now admitted as an independent cardiovascular risk factor (15).

\section{Arterial Aging, A New Risk Factor}

\subsection{Arterial Aging and Risk Factors}

It is widely accepted that carotid-femoral pulse wave velocity (PWV) reflects Early vascular aging (EVA). Pulse wave velocity is an independent (5) cardiovascular risk factor that is better correlated with cardiac morbidity and all causes of mortality, than conventional risk factors, such as diabetes, hypertension, hypercholesterolemia, and tobacco intake $(13,16)$.

This was shown with large arteries stiffening using PWV. Local adverse effects of pulse pressure have not been validated (17). The interference between small arteries and large arteries can be linked to a virtuous circle; remodeling of small arteries and rarefactions of the vasculature that causes an increase in blood pressure, which increases the stiffness of the large vasculature with noble organ damage (heart, kidney, and brain).

The stiffness of large arteries increases pulsed blood pressure (systolic - diastolic blood pressure) and the heart work. Indeed, arteries provide a double role, including the transmission of the blood to the periphery and amortization of the cardiac pulsate pressure.

In fact, large arteries play a capacitive role in the vascular system; they restitute the pulsated energy in the diastolic time. In this diastolic time, coronary arteries will be supplied, and this will maintain diastolic pressure for a better coronary and brain blood supply, and more importantly, it will permit a continuous blood flow. The aorta constitutes of $80 \%$ of elastic tissue, which is why it plays a very important role in the vascular system and the amortizing of the blood pulse.

Different systems exist to assess the aging of arteries. Aortic aging can be evaluated directly by measuring the PWV, using different devices. Pulse wave velocity, measured between carotid and femoral sites, is considered as the gold standard of aortic central aging (18); it is associated with age, hypertension, diabetes, and cholesterol, and also with kidney, heart failure, and cognitive impairment.

The PWV is an important independent predictor of all causes of mortality, especially of cardiovascular morbidity, which has been demonstrated in patients with end stage kidney failure (19). Furthermore, PWV is an independent predictor of arterial stiffness morbidity and mortality in other types of patients with hypertension (5) or diabetes (20).

\section{Factors Impacting AS}

\subsection{Gender}

Pulse wave velocity is impacted by height yet not gender. In fact, people with short height were reported to have high PWV, since the velocity of the pulse wave is defined as the ratio of the distance between 2 measured sites to the time needed by the pulse to travel from one arterial site to another. This risk may be due to the short height of the aortic path of the pulse wave. Studies have shown that healthy females have a significantly higher PWV than males (21). This may be due to a higher stress reaction because of the location of the measurement in the groin. In our experience, there was no difference between males and females in the IPC cohort (health care center in Paris-France) using popmetre for PWV measurement (22). The majority of studies have found no association between PWV and gen$\operatorname{der}(23)$.

\subsection{Tobacco}

Regarding other risk factors, tobacco is a known factor in the development and worsening of cardiovascular diseases. It significantly increases EVA, as measured by the PWV, because of its endothelial and vasoconstriction action (24). Regardless of age, measurements of PWV were significantly higher after smoking. Moreover, PWV is significantly higher in chronic smokers regardless of gender, general health, and physical activity levels. Passive smoking has detrimental effects and increases the risk of myocardial infarction. Recent studies have highlighted that some levels of exposure to smoking liabilities have a detrimental effect on AS, at a level slightly lower than active smoking. Other studies have demonstrated the impact of cigarette smoking on the stiffness of large arteries (25).

\subsection{Obesity}

Obesity has become a global epidemic in rich countries, both in children and in adults. Indeed, the prevalence of overweightness and obesity is more than $60 \%$ in adults 
of the USA and this rate increases in children and adolescents. Obesity is an independent risk for cardiovascular disease and is associated with other co-morbidities, such as type 2 diabetes, hypertension, and sleep apnea (26). It has been recognized that individuals with obesity are at a high risk of EVA, independently of brachial blood pressure, ethnicity, and age (27). Furthermore, it was found that central adiposity is a determining factor for arterial stiffening, independently of other factors such as age, and blood pressure. Similarly, it has been shown that aortic PWV is associated with obesity. Wildman et al. reported that median aortic PWV was $4 \mathrm{~m} / \mathrm{s}$ higher in obese individuals than in normal weight subjects (28).

\subsection{Cholesterol}

High cholesterol levels are associated with high pulse pressure, aortic stiffness, and high central blood pressure, despite normal or low peripheral arterial blood pressure. In addition, LDL cholesterol is an independent risk factor for AS (29).

The decrease in serum cholesterol levels reduces the total cardiovascular mortality (30), by participating in the reduction of AS (31). Statins reduced aortic PWV over a period of 2 years. Simvastatin, associated with homocysteine and folic acid/vitamin B12, were

studied in a research trial (Study of the Effectiveness of Additional Reductions in Cholesterol and Homocysteine) to assess the effects of following an aggressive reduction of lipids. The analysis of the pulse wave was included in a substudy of the research trial to assess the existence of the beneficial effect on AS (3). Recently, a meta-analysis confirmed these assumptions (32).

\section{Arterial Stiffness and Age}

With age, AS tends to increase, along systolic blood pressure and PWV. In particular, arterial stiffness measures the cumulative influence of CV risk factors with time, because age represents both the aging process and the duration of exposure to risk factors. Indeed, arterial stiffness represents true arterial wall damage, whereas other risk factors such as BP, glycaemia, and lipid levels vary during patient follow-up and thus may not be representative enough of the cumulative effects of $\mathrm{CV}$ risk factors on the arterial system.

A decline in coronary artery perfusion is observed with age, as well as increased risk of heart disease (33). The mechanisms of vascular impairment in elderly hypertensive patients look different from those of youth. With aging, the structural alteration of the arterial wall is at the forefront of physiological disorders. Aging is associated with PWV (34) or it could be said that with age structural alterations in the aorta appear (35).

Several studies have shown a positive relationship between PWV and age (36). Pulse wave velocity is more pronounced in individuals over 50 years (PWV increases 1 $\mathrm{m} / \mathrm{sec}$ per decade before age 50, then $2 \mathrm{~m} / \mathrm{sec}$ beyond). The increase of AS with age leads to an increased systolic pressure and pulse pressure (isolated systolic hypertension seniors).

\section{Structural and Functional Rigidity}

The increase in blood pressure is a factor of functional rigidity, while the increase of structural AS leads to increase in systolic blood pressure and pulse pressure. For a balloon, the increase in internal pressure leads to rigidity of the wall, while aging is the key for structural remodeling.

\section{Role of Physical Exercise}

It has been demonstrated that physical exercise decreases AS in patients with coronary artery disease (37) or end stage renal disease (38), and effectively reduces the risk of myocardial ischemia by decreasing myocardial oxygen demand and increasing coronary infusion.

In addition, physical exercises may impact AS related to normal aging. Individuals practicing endurance sports have lower AS than sedentary individuals of the same age and level of blood pressure. Reduced physical activity leads to a decrease in genetic expression

of predisposition to high systemic arterial stiffness (37). The interaction between large arteries and small arteries is illustrated in Figure 1(39). The mean arterial pressure (MAP) and PP are remodeling factors for small and large arteries and the left ventricle. Arteriolar vasoconstriction is secondary to the increase in vasomotor tone, this increases peripheral resistances, leading to a high blood pressure. Arterial remodeling is a structural factor that increases peripheral resistance at the beginning of a real vicious cycle of increased stiffness and loss of compliance.

Arterial stiffening is an indirect result of aging and hypertension or other types of stress, such as chemical or oxidative stress. Studies have shown that PWV at the upper limb does not correlate with aging; a poor correlation may be found at the lower limb. However, when it comes to the aortic path, this correlation is very significant (40). 


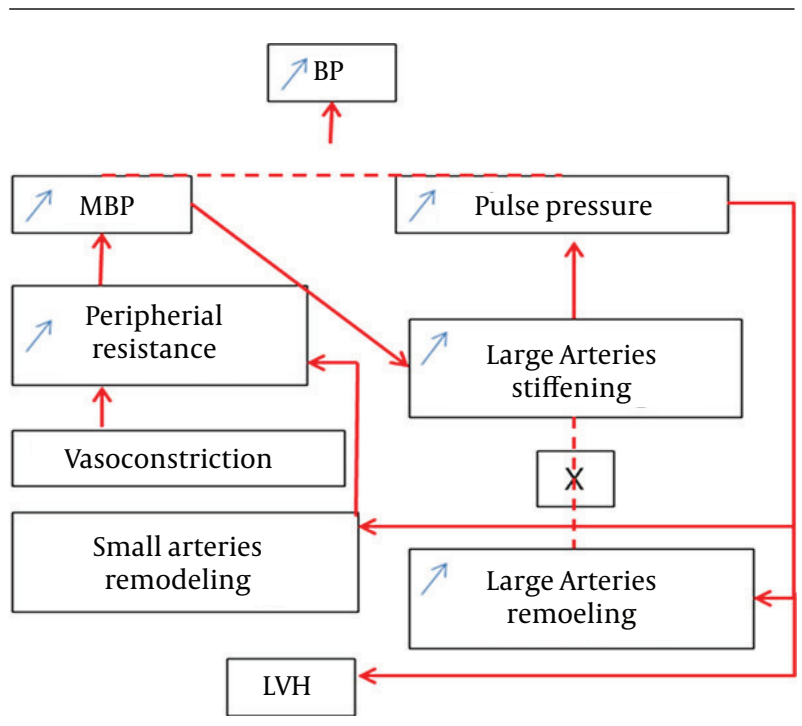

Figure 1. Pathogenesis of Arterial and Arteriolar Remodeling in Hypertension, According to Laurent et al.; BP is Blood Pressure, MBP Mean Blood Pressure, and LVG Left Ventricular Hypertrophy.

\section{Mathematical Model of the Pulse Wave Velocity and Arteries Path}

The PWV, defined as the travelled distance divided by the travel time, is measured using 2 similar pressure sensors located on the 2 sites of an arterial segment; the time needed by the pulse to travel from one arterial site to another and the distance between the measured sites was measured in this study (see Figure 2). The order of magnitude of the PWV varies between 5 to $15 \mathrm{~m} / \mathrm{s}$. It is different from the blood flow velocity in arteries, which is about 20 to $30 \mathrm{~cm} / \mathrm{s}$ in large arteries. The aorta is the principal vessel of interest when measuring arterial stiffness because the thoracic and abdominal aorta are the principal sites for arterial buffering function, and aortic PWV has proved to be an independent predictor of outcome in various populations. However, all accessible arterial territories are potentially interesting. For instance, the forearm circulation corresponds to BP measurement, and the lower limb arteries are a classic site for atherosclerosis. The measurement of carotid stiffness also carries important prognostic information, because the carotid artery is also a possible site for atherosclerosis. Some devices measure arteries stiffening indices using transfer functions. These indices do not have any added value than that of brachial blood pressure measurement.

Pulse wave velocity depends on the visco-elastic characteristics of the arterial wall. It reflects the quality of the artery to "attenuate" the pulsate shock. Modeling the PWV has its origin in the works of Newton, who noted in a math-
Figure 2. Waves 1 and 2 Through the Artery Beneath the Sensor Successively in the Direction of the Lower Arrow

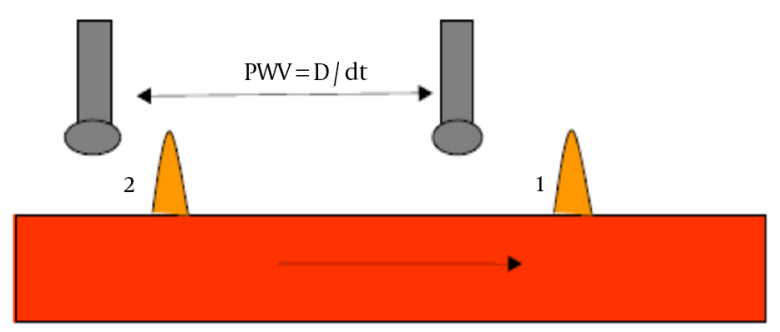

The transit time (dt) between the pulse waves, and the distance (D) between the two sensors were taken in account.

ematical equation the relationship between velocity, elasticity, and density of the material.

Thomas Young redefined PWV using the relationship between pressure variation and changes in volume for a given arterial segment. Moens and Korteweg worked on the modeling of PWV, according to pulse pressure and compliance (Figure 3), according to Armantano and Levenson (41). Pulse wave velocity is proportional to the variation of blood pressure and to the variation of the artery diameter, which depends on the elasticity of the artery wall. Finally, PWV is proportional to the square root of the variation in blood pressure over that of the diameter and it depends on blood density.

Figure 3. PWV as a Function of Pressure and Diameter of the Artery

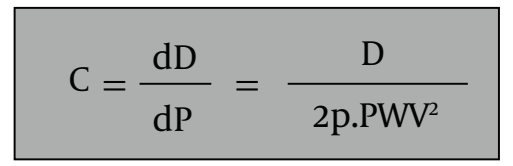

We can deduce

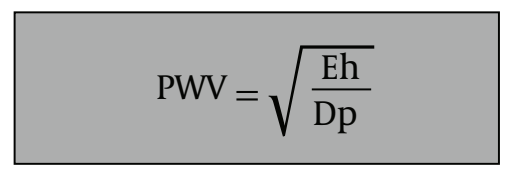

and

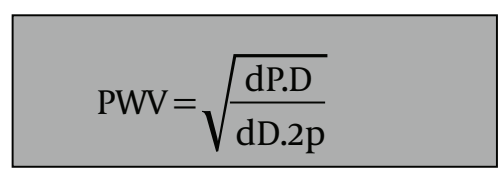

$\mathrm{C}$ is the arterial compliance, $\mathrm{PWV}$ is the pulse wave velocity, $\mathrm{E}$ is the elasticity modulus, $h$ is the thickness of the arterial wall, D is the arterial internal end-diastolic diameter and $\mathrm{p}$ is the density of the blood. $\mathrm{dD}$ the variation of the arterial diameter, and $\mathrm{dP}$ the blood pressure variation.

The measurement of PWV is of growing interest in this century. This concerns clinicians, physiologists, and 
engineers. Mathematical modeling of a tube with inhomogeneous liquid inside is very hard, especially in the case of a fluid with outstanding particle, pulsate and noncompressible flow, and propagating in elastic conduits.

Most of the modeling methods were described in the nineteenth and twentieth centuries. In the last decade, this subject has interested many Clinicians (O. Rourke, Safar, Lawrence, and Martyn). The direct measurement of arterial elasticity by the ratio between pressure and diameter using PWV was reviewed by Hickler in 1990, and Lehman Hayashi in 1999 and in 2002. Since then, there has been growing interest in non-invasive methods to measure AS, which reflects arteries compliance, using advanced technology to measure and signal processing of biological pulses.

\section{The Carotid-Femoral Pulse Wave Velocity}

Several methods have been developed to noninvasively measure arterial compliance. Most of them are based on the determination of the carotid to femoral pulse wave velocity (PWVcf). The PWV between the common carotid artery (CCA) and the common femoral artery (PWVcf) is measured directly and corresponds to a well-accepted propagative model of the arterial system (14). Because it includes the aortic and aorto-iliac pathway, it is clinically relevant, because the big thoracic arteries (aorta and its first branches) represent the hemodynamic load that the left ventricle "sees" and are therefore responsible for a large part of the pathophysiological influence of arterial stiffness. Most epidemiologic studies demonstrating the predictive value of aortic stiffness for CV events have used carotid-femoral PWV. The CfPWV is considered as the gold standard for measuring arterial stiffness (13). In contrast, PWV measured outside the aortic track, for instance on the upper (brachial-radial PWV) or lower limb (femoral-tibial PWV), does not provide any additional predictive value for patients with end-stage renal disease. The pulse wave is generated by the contraction of the left ventricle, which causes initial shock pulse, counter the blood in the aorta. The pressure wave is recorded at these 2 sites (carotid and femoral) using sensors alternately on the carotid and the femoral site (42). Figure 4 shows the locations and the distance between the carotid and the femoral sites. To date, the PWVcf has been the best surrogate of vascular stiffness. It is now considered as a major point in cardiovascular risk management (4).

The conventional method for measuring direct PWV, using Pulsed Doppler sensor, seems tedious and expensive. Conventional methods use pressure sensors (piezoelectric, Complior®, Alam medical France; SphygmoCor®, Atcor, Australia; PulsPen®, Diatecne, Italy) laid in 2 points of an
Figure 4. Large Arteries According to Boutouyrie et al.

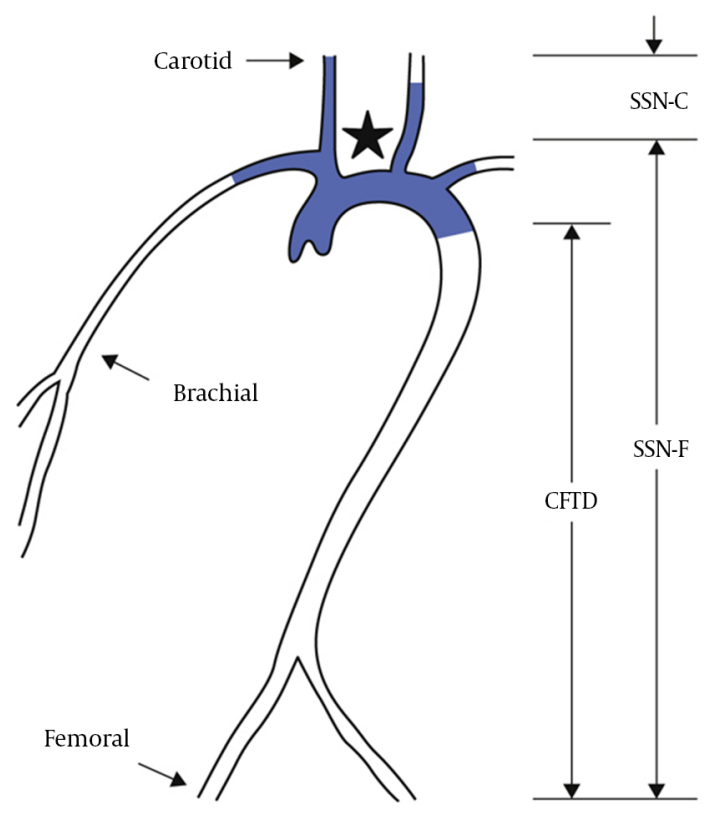

SSN-C, distance from the carotid sensor to the sternal node; SSN-F:, distance from the sternal node to the femoral sensor; CFTD, SSN-F minus SSN-C.

arterial segment. They detect the transit time between 2 points; the velocity of the pulse wave is defined as the ratio of the distance $(\mathrm{D})$ between the 2 probes divided by the wave transit time (dt) (Figure 2). The distance is measured on the body surface between the carotid and the femoral sites. This method does not perfectly reflect the reality of the length of the arterial path, yet, it is considered as the gold standard. Controversies exist on how to measure this distance, given the carotid bifurcation (Figure 4). These methods overestimate the aortic path in obese subjects.

\section{Indirect Methods}

Other AS assessment methods use transfer functions. These techniques rely on simplified circulation models and are used when a single site for measuring the pressure waveform is required. They primarily measure the blood pressure at the arm using an ordinary device. The augmentation index and the central blood pressure are calculated according to age, blood pressure, and the morphology of the pulse wave. These methods and indices do not provide any additional predictive value beyond that of blood pressure measurement (43). 
Devices close to the reference method apparatus (Omron®, Collin, Japan) use the pulse wave velocity and deduce the compliance using arms and legs cuffs. Brachial Ankle PWV(PWVba) measures arterial stiffness indices. The difference time (Dt) between the two fronts of the brachial and ankle pulse waves are taken into account. The direct distance from the arm to the ankle is measured, and is divided by dt, to obtain the PWVba.

The QKD is a concept that measures compliance regional outpatient (Diasis®, Novacor, France). Other devices, such as Tensioclinic Arterigraph® (Hungary), Mobilograph, are based on the enhancement of the reflected wave signal on an oscillometric plot when supra-systolic occlusion is obtained by a cuff on the arm. These "onepoint measurements" of a velocity, use transfer functions, and they are called stiffness indices, yet, they do not have the value of 2 points of measurement of the aortic pulse wave velocity.

Physioflow® is a method based on impedance probes and they measure the flow to estimate the compliance of the aorta. Weinmann and Sapuznikov (44) have described a method that measures the pulse rate using photodiodes that allows the detection of pulse wave. This method is considered reproducible. The waveform sensed in fingertips has the same characteristics as the radial wave.

Finally, a recently developed is pOpmetre $\AA$ (Axelife SAS, France). It is based on the assumption that the arteries of the upper limbs are of the same constitution of that of the lower limbs. They are muscular conducting arteries and not elastic. The lack of stiffening through aging of these arteries has been demonstrated. The pOpmetre $₫$ is also based on measuring the transit time of the pulse wave between the finger and the toe pulpar arteries (45) using photodiode sensors. The data provided by this apparatus are linked to aging (46), and has excellent intersession repeatability $(\mathrm{SD} /$ Mean $=5.7 \%)$ and a good correlation with the standard method. The algorithm was reviewed and the data of 101 subjects was used to compare pOpmetre $®$ and the carotid to femoral gold standard method, and the 2 methods were very highly correlated $(\mathrm{r}=0.91)$; mean $\pm \mathrm{SD}$ $9.6 \pm 1.7$ vs $9.7 \pm 1.6$ (47); the bias between the 2 methods was $0.3 \mathrm{~m} / \mathrm{s}$ using Bland and Altmann diagram. These results suggest that pOpmetre $® \mathrm{PWV}$ is a very robust surrogate for the gold standard carotid to femoral PWV. Other data were obtained in different pathologies with pOpmetre: in sickle cell disease (48), link to anti-phospholipids syndrome (49); pOpmetre PWV was associated to blood concentration of the Ac-APL. In systemic sclerosis PWV was higher in comparison to controls (50). The PWV with pOpmetre increased from control, obese, patients with diabetes, and obese-diabetic patients (51). It was linked to carotid plaques in metabolic syndrome (52) while Ankle
Brachial Index was not different. The PWV with pOpmetre was liked to the Glomerular Filtration Rate in kidney function of transplants (53). Arterial Stiffness has been studied in many pathological populations for cardiovascular risk assessment, such as in patients with diabetes (54) and kidney transplant recipients (55). There is more than 2000 papers every year dealing with Pulse Wave velocity. pOpmetre was studied in a cardiac rehabilitation program and showed a link between the 6-minute walk test, PWV and maximal workload (MWL) that increased from $94.9 \pm 35$ to $116 \pm 37$ Watts and the 6-minute walking test (6MWT) from $430 \pm 113$ to $505 \pm 106 \mathrm{~m}(\mathrm{P}<0.0001)$. The PWV decreased from $9.16 \pm 3.0$ to $8.39 \pm 2.5 \mathrm{~m} / \mathrm{s}(\mathrm{P}<0.008)$. A positive correlation was found with age $(\mathrm{r}=0.38 ; \mathrm{P}<0.0003)$ and inverse correlation with maximal workload $(\mathrm{r}=-0.34$; $\mathrm{P}<0.001)$ and 6MWT $(\mathrm{r}=-0.22 ; \mathrm{P}<0.003)(56)$, as shown by Khoshdel et al. (57) in the link between kidney failure and exercise. Finally, at a medical health care center (22) they found that the PWV data in healthy individuals with pOpmetre $®(\mathrm{~N}=700)$ was exactly overlapping with that of 1500 cfPWV. While the carotid-femoral methods have a repeatability of around $12.3 \%$ to $14.5 \%$ (58), this latter method seems feasible in every day practice in outpatient clinics.

Nevertheless, the carotid to femoral PWV is used today in research centers, and the most important difference between these methods is that pOpmetre users need 2 hours of training to get a result within 20 seconds while 3 weeks is required to learn the carotid to femoral PWV and 15 minutes is needed to obtain results. With pOpmetre, there is no need to undress the patient for the femoral artery access and seems to be stress less and more acceptable for cultural reasons.

\section{Conclusions}

It has been shown that the measurement of vascular aging with PWV is a decisive biomarker for the early detection and management of at risk patients. Studies show the difficulties of implementation of the PWVcf. Indeed, 20\% of cases tested for PWVcf are not measurable (59), and from personal experience, $\mathrm{PWVcf}$ was possible only in 80 people aged 70 and over among 120 tested patients because of stiff neck or the thickness of the abdominal apron. In the elderly, as in young adults, AS is a parameter to be taken into account in cardiovascular evaluation and general screening. It should be taken into account in various diseases specific to aging, such as osteoporosis and cognitive disorders $(60,61)$. Measuring vascular aging has been made simple, easy, and reliable, given its importance in several common diseases. This is recommended on a bi-annual basis for monitoring and management of vascular risk, as 
approved by the European and French societies of hypertension, and that of cardiology. The link between coronary artery stenosis is at the same level of significance as that of coronary arteries scoring (62). It adds $10 \%$ to $20 \%$ to the coronary heart disease risk score (63) and can be used in primary care screening for cardiovascular risk.

Noninvasive measurement was permitted at the end of the twentieth century and early twenty-first century, thanks to improved techniques capturing and signal processing to obtain the pulse signal with current technologies. pOpmetre $®$ is a user-friendly equipment, simple and fast, with a short learning curve and reliable enough to measure arterial aging, suitable for people of all ages, in mass screening to better prevent, and manage cardiovascular therapy.

\section{References}

1. Khot UN, Khot MB, Bajzer CT, Sapp SK, Ohman EM, Brener SJ, et al. Prevalence of conventional risk factors in patients with coronary heart disease. JAMA. 2003;290(7):898-904. doi: 10.1001/jama.290.7.898. [PubMed: 12928466].

2. Coca A, Olsen M, Officer FL, Kahan T. The European Society of Cardiology Council on Hypertension. Eur Heart J. 2016:924-5.

3. Cockcroft JR, Webb DJ, Wilkinson IB. Arterial stiffness, hypertension and diabetes mellitus. J Hum Hypertens. 2000;14(6):377-80. [PubMed: 10878698].

4. Laurent S, Cockcroft J, Van Bortel L, Boutouyrie P, Giannattasio C, Hayoz D, et al. Expert consensus document on arterial stiffness: methodological issues and clinical applications. Eur Heart J. 2006;27(21):2588-605. doi: 10.1093/eurheartj/ehl254. [PubMed: 17000623].

5. Laurent S, Boutouyrie P, Asmar R, Gautier I, Laloux B, Guize L, et al. Aortic stiffness is an independent predictor of all-cause and cardiovascular mortality in hypertensive patients. Hypertension. 2001;37(5):123641. [PubMed: 11358934].

6. Mancia G, Bombelli M, Facchetti R, Madotto F, Quarti-Trevano F, Polo Friz $\mathrm{H}$, et al. Long-term risk of sustained hypertension in whitecoat or masked hypertension. Hypertension. 2009;54(2):226-32. doi: 10.1161/HYPERTENSIONAHA.109.129882. [PubMed: 19564548].

7. Selenta C, Hogan BE, Linden W. How often do office blood pressure measurements fail to identify true hypertension? An exploration of white-coat normotension. Arch Fam Med. 2000;9(6):533-40. [PubMed: 10862216].

8. Kannel WB, Wolf PA, McGee DL, Dawber TR, McNamara P, Castelli WP. Systolic blood pressure, arterial rigidity, and risk of stroke. The Framingham study. JAMA. 1981;245(12):1225-9. [PubMed: 7206111].

9. Castelli WP. [Framingham 36 years later]. Arch Mal CoeurVaiss. 1987;80 Spec No:11-5. [PubMed: 3113392].

10. Cressman MD, Gifford RW Jr. Hypertension and stroke. J Am Coll Cardiol. 1983;1(2 Pt 1):521-7. [PubMed: 6826961].

11. Krantz MJ, Long CS, Hosokawa P, Karimkahani E, Dickinson M, Estacio RO, et al. Pulse wave velocity and carotid atherosclerosis in white and Latino patients with hypertension. BMC Cardiovasc Disord. 2011;11:15. doi: 10.1186/1471-2261-11-15. [PubMed: 21481252].

12. Meaume S, Benetos A, Henry OF, Rudnichi A, Safar ME. Aortic pulse wave velocity predicts cardiovascular mortality in subjects $>70$ years of age. Arterioscler Thromb Vasc Biol. 2001;21(12):2046-50. [PubMed: 11742883].

13. Vlachopoulos C, Aznaouridis K, Stefanadis C. Prediction of cardiovascular events and all-cause mortality with arterial stiffness: a system- atic review and meta-analysis. J Am Coll Cardiol. 2010;55(13):1318-27. doi: 10.1016/j.jacc.2009.10.061. [PubMed: 20338492].

14. Yusuf S, Hawken S, Ounpuu S, Dans T, Avezum A, Lanas F, et al. Effect of potentially modifiable risk factors associated with myocardial infarction in 52 countries (the INTERHEART study): case-control study. Lancet. 2004;364(9438):937-52. doi: 10.1016/S0140-6736(04)17018-9. [PubMed: 15364185].

15. Rosengren APJ, Dallongeville J, Camm AJ, Luscher TF, Serruys PW. Prevention of Cardiovascular Disease in The ESC Textbook of Cardiovascular Medicine. Oxford University Press; 2009.

16. Van Bortel LM, Laurent S, Boutouyrie P, Chowienczyk P, Cruickshank JK, De Backer T, et al. Expert consensus document on the measurement of aortic stiffness in daily practice using carotidfemoral pulse wave velocity. J Hypertens. 2012;30(3):445-8. doi: 10.1097/HJH.ob013e32834fa8bo. [PubMed: 22278144].

17. Laurent S, Briet M, Boutouyrie P. Large and small artery crosstalk and recent morbidity-mortality trials in hypertension. Hypertension. 2009;54(2):388-92. doi:10.1161/HYPERTENSIONAHA.109.133116. [PubMed: 19546376].

18. Boutouyrie P, Briet M, Collin C, Vermeersch S, Pannier B. Assessment of pulse wave velocity. Artery Res. 2009;3(1):3-8. doi: 10.1016/j.artres.2008.11.002.

19. London GM, Blacher J, Pannier B, Guerin AP, Marchais SJ, Safar ME. Arterial wave reflections and survival in end-stage renal failure. Hypertension. 2001;38(3):434-8. [PubMed: 11566918].

20. Cruickshank K, Riste L, Anderson SG, Wright JS, Dunn G, Gosling RG. Aortic pulse-wave velocity and its relationship to mortality in diabetes and glucose intolerance: an integrated index of vascular function?. Circulation. 2002;106(16):2085-90. [PubMed:12379578].

21. Brown MJ. Similarities and differences between augmentation index and pulse wave velocity in the assessment of arterial stiffness. QJM. 1999;92(10):595-600. [PubMed: 10627881].

22. Adebayo RA, Balogun MO, Akinola NO, Akintomide AO. Cardiovascular changes in sickle cell anaemia. Niger J Med. 2002;11(4):145-52. [PubMed: 12955989].

23. Cecelja M, Chowienczyk P. Dissociation of aortic pulse wave velocity with risk factors for cardiovascular disease other than hypertension: a systematic review. Hypertension. 2009;54(6):1328-36. doi: 10.1161/HYPERTENSIONAHA.109.137653. [PubMed: 19884567].

24. Mahmud A, Feely J. Effects of passive smoking on blood pressure and aortic pressure waveform in healthy young adults-influence of gender. BrJ Clin Pharmacol. 2004;57(1):37-43. [PubMed: 14678338].

25. Vlachopoulos C, Alexopoulos N, Panagiotakos D, O'Rourke MF, Stefanadis C. Cigar smoking has an acute detrimental effect on arterial stiffness. Am J Hypertens. 2004;17(4):299-303. doi: 10.1016/j.amjhyper.2003.12.014. [PubMed: 15062882].

26. Poirier P, Giles TD, Bray GA, Hong Y, Stern JS, Pi-Sunyer FX, et al. Obesity and cardiovascular disease: pathophysiology, evaluation, and effect of weight loss. Arterioscler Thromb Vasc Biol. 2006;26(5):968-76. doi: 10.1161/01.ATV.0000216787.85457.f3. [PubMed:16627822].

27. Safar ME, Czernichow S, Blacher J. Obesity, arterial stiffness, and cardiovascular risk. J Am Soc Nephrol. 2006;17(4 Suppl 2):S109-11. doi: 10.1681/ASN.2005121321. [PubMed:16565231].

28. Wildman RP, Mackey RH, Bostom A, Thompson T, Sutton-Tyrrell K. Measures of obesity are associated with vascular stiffness in young and older adults. Hypertension. 2003;42(4):468-73. doi: 10.1161/01.HYP.0000090360.78539.CD. [PubMed: 12953016].

29. Wilkinson IB, Prasad K, Hall IR, Thomas A, MacCallum H, Webb DJ, et al. Increased central pulse pressure and augmentation index in subjects with hypercholesterolemia.JAm Coll Cardiol. 2002;39(6):1005-11. [PubMed: 11897443].

30. Wilkinson IB, Cockcroft JR. Cholesterol, endothelial function and cardiovascular disease. Curr Opin Lipidol. 1998;9(3):237-42. [PubMed: 9645507].

31. Ferrier KE, Muhlmann MH, Baguet JP, Cameron JD, Jennings GL, Dart $\mathrm{AM}$, et al. Intensive cholesterol reduction lowers blood pressure and 
large artery stiffness in isolated systolic hypertension. J Am Coll Cardiol. 2002;39(6):1020-5. [PubMed: 11897445].

32. Sahebkar A, Pecin I, Tedeschi-Reiner E, Derosa G, Maffioli P, Reiner Z. Effects of statin therapy on augmentation index as a measure of arterial stiffness: A systematic review and meta-analysis. Int J Cardiol. 2016;212:160-8. doi: 10.1016/j.ijcard.2016.03.010. [PubMed: 27038725].

33. Mitchell GF, Parise H, Benjamin EJ, Larson MG, Keyes MJ, Vita JA, et al. Changes in arterial stiffness and wave reflection with advancing age in healthy men and women: the Framingham Heart Study. Hypertension. 2004;43(6):1239-45. doi: 10.1161/01.HYP.0000128420.01881.aa. [PubMed: 15123572].

34. Khoshdel AR, Thakkinstian A, Carney SL, Attia J. Estimation of an age-specific reference interval for pulse wave velocity: a meta-analysis. J Hypertens. 2006;24(7):1231-7. doi: 10.1097/01.hjh.0000234098.85497.31. [PubMed: 16794467].

35. Oliver JJ, Webb DJ. Noninvasive assessment of arterial stiffness and risk of atherosclerotic events. Arterioscler Thromb Vasc Biol. 2003;23(4):554-66. doi: 10.1161/01.ATV.0000060460.52916.D6. [PubMed: 12615661].

36. Nichols WW, O'Rourke M, Vlachopoulos C. McDonald's blood flow in arteries: theoretical, experimental and clinical principles. CRC press; 2011.

37. Edwards DG, Schofield RS, Magyari PM, Nichols WW, Braith RW. Effect of exercise training on central aortic pressure wave reflection in coronary artery disease. Am J Hypertens. 2004;17(6):540-3. doi: 10.1016/j.amjhyper.2003.12.001. [PubMed: 15177529].

38. Mustata S, Chan C, Lai V, Miller JA. Impact of an exercise program on arterial stiffness and insulin resistance in hemodialysis patients. J Am Soc Nephrol. 2004;15(10):2713-8. doi: 10.1097/01.ASN.0000140256.21892.89. [PubMed: 15466276].

39. Tropeano AI, Laurent S. Consequences de l'atteinte vasculaire silencieuse au cours de l'hypertension arterielle et de l'hyperglycemie. Medecine therapeutique Cardiologie. 2003;1(3):243-52.

40. van der Heijden-Spek JJ, Staessen JA, Fagard RH, Hoeks AP, Boudier HA van Bortel LM. Effect of age on brachial artery wall properties differs from the aorta and is gender dependent: a population study. Hypertension. 2000;35(2):637-42. [PubMed: 10679510].

41. Armentano RASA, Levenson J. Interet de l'enregistrement de la vitesse de l'onde de pouls pour l'etude de la compliance arterielle : valeur, diagnostic et pronostic. STV. 1995;7:265-70.

42. Boutouyrie PBM, Collin C. , Vermeersch S, Pannier B. Assessment of pulse wave velocity. Artery Res. 2009;3:3-8.

43. Song BG, Park JB, Cho SJ, Lee SY, Kim JH, Choi SM, et al. Pulse wave velocity is more closely associated with cardiovascular risk than augmentation index in the relatively low-risk population. Heart Vessels. 2009;24(6):413-8. doi: 10.1007/s00380-009-1146-1. [PubMed: 20108072].

44. Weinman J, Sapoznikov D. Equipment for continuous measurements of pulse wave velocities. Med Biol Eng. 1971;9(2):125-38. [PubMed: 5152362].

45. Zhang JBE, Hallab M, Boutouyrie P, Laurent S. Etude de validation d'un nouveau dispositif de mesure de la rigidite arterielle : Le pOpmètre $₫$. Archives des maladies du coeur et des vaisseaux. 2011;3:95.

46. Hallab M, Pichierri S, Boin JM, Tramblay M, Chevalet P, Berrut G. [A new index to evaluate arterial ageing independently of arterial blood pressure: pOpscore((R))]. Ann Cardiol Angeiol (Paris). 2012;61(3):184-7. doi: 10.1016/j.ancard.2012.04.014. [PubMed: 22621845].

47. Obeid H, Khettab H, Hallab M, Boutouyrie P, Laurent S. Comparison of arterial stiffness assessed by pOpmètre $®$ with arterial stiffness assessed by applanation tonometry: a clinical study. Artery Res.
2016;16:72.

48. Ouedraogo V, Signolet I, Diaw M, Hallab M, Leftheriotis G. Arterial stiffness in the african heterozygous and homozygous sickle cell disease. Acta Physiologica. 2015;214:57.

49. Hallab M, Leftheriotis G, Belizna C. Arterial stiffness measured with pOpmètre $®$ in primary anti-phospholipids syndrome. Artery Res 2014;8(4):135. doi: 10.1016/j.artres.2014.09.108.

50. Abdoulaye B, Maïmouna T, Valentin O, Mor D. Arterial Stiffness Measured by Popmètre $®$ in Patients with Systemic Sclerosis.JPhysiol Phar macol Adv. 2015;5(10):739-43.

51. Mohammedi K, Compaore A, Potier L, Belhatem N, Feron M, Matallah $\mathrm{N}$, et al. Outpatient measurement of arterial stiffness in patients with type 2 diabetes and obesity. J Diabetes. 2017;9(3):237-42. doi: 10.1111/1753-0407.12405. [PubMed: 27059393].

52. Hallab M, Collette M, Terrier-Barbeau C, Legrand M, Ducluzeau PH Berrut $G$, et al. [Regional and peripheral arterial stiffness measured by pOpmetre(R) in patients with Cvx risk factor, link with carotid plaques]. Ann Cardiol Angeiol (Paris). 2013;62(3):189-92. doi 10.1016/j.ancard.2013.04.001. [PubMed: 23721988].

53. Hallab M, Bertin S, Gatault P, Barbet C, Lebranchu Y, Buchler M, et al. 0438: Pulse wave velocity with pOpmetre $®$ independently correlates with glomerular filtration rate in renal transplant patients. Arch Cardiovasc Dis Suppl. 2014;6:55.

54. Khoshdel AR, Carney SL, Trevillian P, Gillies A. Evaluation of arterial stiffness and pulse wave reflection for cardiovascular risk assessment in diabetic and nondiabetic kidney transplant recipients. Iran J Kidney Dis. 2010;4(3):237.

55. Khoshdel AR, Carney SL. Arterial Stiffness in Kidney Transplant Recipients. Urol J. 2008;5(1):3-14.

56. Obeid H, Pavy B, Hallab M, Darchis J, Merle E. Measuring arterial stiffness with pOpmètre $®$ in cardiac rehabilitation program. Artery Res. 2016;16:86.

57. Khoshdel AR, Carney SL, White S, Gillies A. Hemodynamic Response to Exercise for Prediction of Development of Kidney Failure. Iran J Kidney Dis. 2016;10(5)

58. Salvi P. Nouvelles approches méthodologiques pour l'évaluation du vieillissement des gros troncs artériels par l'étude de la distensibilité artérielle et de l'analyse de la courbe de la pression artérielle chez l'homme. ; 2015.

59. Inoue $\mathrm{N}$, Maeda $\mathrm{R}$, Kawakami $\mathrm{H}$, Shokawa $\mathrm{T}$, Yamamoto $\mathrm{H}$, Ito $\mathrm{C}$ et al. Aortic pulse wave velocity predicts cardiovascular mortality in middle-aged and elderly Japanese men. Circ J. 2009;73(3):549-53. [PubMed: 19179770].

60. Mackey RH, Sutton-Tyrrell K, Vaitkevicius PV, Sakkinen PA, Lyles MF Spurgeon HA, et al. Correlates of aortic stiffness in elderly individuals: a subgroup of the Cardiovascular Health Study. Am J Hypertens. 2002;15(1 Pt 1):16-23. [PubMed: 11824854].

61. Hanon O, Haulon S, Lenoir H, Seux ML, Rigaud AS, Safar M, et al. Relationship between arterial stiffness and cognitive function in elderly subjects with complaints of memory loss. Stroke. 2005;36(10):2193-7. doi: 10.1161/01.STR.0000181771.82518.1c. [PubMed: 16151027].

62. Park JH, Cho JY, Joo HJ, Hong SJ, Yu CW, Lim DS. Correlation between the severity of coronary artery stenosis and coronary artery calcium, carotid atherosclerosis, arterial stiffness and left ventricular mass index in metabolic syndrome patients. J Am College Cardiol. 2015;65(10):eA1121.

63. Simon A, Chironi G, Levenson J. Comparative performance of subclinical atherosclerosis tests in predicting coronary heart disease in asymptomatic individuals. Eur Heart J. 2007;28(24):2967-71. doi: 10.1093/eurheartj/ehm487. [PubMed: 17967818] 